\title{
BACKACHE IN PREGNANCY;
}

\section{ROLE OF PHYSIOTHERAPY IN ITS RELIEF}

Dr. Nadeem Shahzad, Farhat Aslam, Dr. Aisha Malik, Asif Hanif

ABSTRACT... Introduction: Backache is a common problem during pregnancy that is faced by almost one quarter of all pregnant women worldwide. Objectives: To find an association between backache and pregnancy with respect to obesity and to evaluate the effect of physiotherapy for relief of pain. Methodology: This longitudinal observational \& randomized control study was conducted on pregnant females for a period of six months. 150 females fulfilling the inclusion criteria were enrolled into two groups i.e. obese patients (BMI $>29.9)$ and non obese patients (BMI<29.9). All information was recorded on a Performa that was later entered and analyzed using SPSS-11.5. Results: The mean age of all patients was $33.67 \pm 6.73$ years with overall average gestational age of $27.47 \pm 5.19$ weeks. Flexed posture was observed in $90(60 \%)$ patients and 60(40\%) had very bad sitting habit. There were 80 (53.3\%) obese and $70(46.7 \%)$ non-obese patients. Lordosis was observed in 50 cases, straight spine was observed in 90 cases while 60 patients had no straight spine. Most females reported that pain started during the $1^{\text {st }}$ trimester (110) but only 40 females reported that they developed pain in the $2 \mathrm{nd}$ trimester.100 females reported that pain was continuous while 50 had intermittent. There were 50 (33\%) patients who had severe backache while $100(66.7 \%)$ had worse possible pain which was regressed to no pain in 140(93.3\%) patients at final follow up visit and only 10 (6.7\%) had moderate pain after physiotherapy. The difference between pre and post physiotherapy was statistically significant. Both obese and non-obese patients were reported to be benefited but better results were found in non-obese patients. Conclusions: We conclude that physiotherapy is effective in reducing the backache in pregnant females and has no side effects on fetus and mother. Also, more effective results can be achieved through physiotherapy in non-obese patients compared to obese patients. Thus, Physiotherapy can be recommended as the first line treatment for pregnant females.

Key words: Lower back pain (LBP), physiotherapy, obese, pregnancy

Article Citation

Shahzad N, Aslam F, Malik A, Hanif A. Backache in pregnancy; role of physiotherapy in its relief. Professional Med J 2013;20(4): 550555.

\section{INTRODUCTION}

Backache is a common complaint in pregnant females and presents a constant obstacle during pregnancy when performing activities of daily living ${ }^{1}$. It is reportedly observed as a cause of sick leave from work in as many as $30 \%$ of pregnant ladies, persist $>6$ months in $6 \%$ of cases and disturbs sleep in over one third pregnant women ${ }^{2,3}$. The incidence of backache in pregnancy ranges from $24 \%$ to $90 \%$ for different populations as reported variously ${ }^{4,5}$. Two common patterns of backache in pregnancy are described by experts; lumbar pain occur in the area of lumbar vertebrae in lower back and posterior pelvic pain is felt in the back of the pelvis. However, in some women the symptoms of both types of backache can occur ${ }^{6}$.

Two of the most debated risk factors for backache during pregnancy include age and parity. Several studies report a higher prevalence of backache with increasing age while other correlate a higher risk of back pain with younger age. Yet some other studies even failed to find any association between these two entities ${ }^{7,8}$. Such baffling argument is also continuing for status of multiparty as a risk factor, where some evidences support while other deny any association between the two ${ }^{9}$. Additionally, Ethnicity, low socioeconomic class, occupation and vocational risks have also been identified as risk factors, while contrarily some other labeled factors like maternal age, weight, weight gain along with baby weight have been confirmed not to have an effect on backache ${ }^{10,11}$. Parity, gestational age ,exercise habits before and after pregnancy ,BMI, satisfaction at work, type of bed and previous history of back pain are other parameters have also been studied more sparingly, but do not appear to have sufficient evidence to be proved of having association with backache in pregnancy ${ }^{12,13}$. 
Obesity is associated with various musculoskeletal disorders and there is a linear association between low back pain and $\mathrm{BMI}^{14}$. The $\mathrm{BMI}$ and pain association is consistent with what has been observed among persons with obesity seeking weight loss and weight reduction can reduce reports of musculoskeletal pain ${ }^{15}$. LBP during pregnancy can present with variety of symptoms. Almost $45.5 \%$ to $65 \%$ women feel radiation of pain into the buttocks whilst as many as half report experiencing low back pain radiating down one leg and 25\% down both legs. Standing, sitting, lying, Coughing, sneezing. Staining during bowel movements and walking can either be relieving or aggravating factors ${ }^{16}$. Physical examination typically generates confusion in evaluating the source of low back pain. Moreover, commonly used assessment tools of backache in pregnancy such as visual analog scale and pain diagrams drawn by patients are often inadequate in distinguishing between lumber and posterior pelvic pain ${ }^{17}$. The lumber pain, nevertheless, is similar to the clinical presentation experienced by non pregnant patient and is easier to correctly diagnose.

Initial treatment for pregnant patients with backache are heat and ice, acetaminophen may help to relieve the pain as Non-steroidal anti inflammatory drugs are relatively contraindicated in pregnancy. Massage therapy may also provide short term pain relief ${ }^{19}$. Proper posture can prevent unnecessary stress on the low back therefore pregnant women are suggested to avoid wearing high-heeled shoes that accentuate lumbar lordosis and increase shearing stress on back and sacrum $^{20}$. One of the most common but controversial treatment option for backache in pregnancy is physical therapy, the goal of exercise in pregnancy is to improve or maintain the muscle tone and not to control weight gain or correct posture ${ }^{21}$.

\section{MATERIAL AND METHODS}

This study was conducted at Obstetrics \& Gynecology Department Lady Willingdon Hospital Lahore for a period of six months from June 2011 to Dec 2011. This was a longitudinal observational and randomized controlled study in which 150 pregnant females who fulfilled the inclusion criteria were included. This criteria was to select those pregnant females with age $20-40$ years with gravid $>2$ of gestational age $>12$ weeks and having singleton pregnancy. Whereas, those females having renal stones, history of Disc Herniation, UTI, history of congenital deformity of spine and traumatic injury were excluded from the study. Informed consent was obtained from each patient and then demographic details like name, age, sex, height, weight, gravid etc. were noted. The patients were enrolled in to two groups i.e. non-obese patients $(\mathrm{BMl}<29.9)$ and obese patients (BMI $>29.9$ ). All the patients were assessed for outcome of different back pain. Backache was evaluated by clinical and physical assessment by visual analogous scale. Hemoglobin \%( HB) was taken and the anemic patients were categorized for $\mathrm{HB}<10$. Physiotherapy was done and all the patients were followed till 6 weeks to note the final outcome. All the in formations were noted on a structured Performa, which was later entered and analyzed using SPSS-11.5. Categorical variables were expressed as frequency and percentages whereas continuous variables was expressed as Mean \pm SD. Chi-square test was applied to see the association between backache and repeated pregnancies with respect to obesity and anemia. A Pvalue $<0.05$ was considered as statistically significant.

\section{RESULTS}

There were 150 patients included in the study with an overall mean age was $33.67+6.73$ years. Mean gestational age of females presented with backache was $27.47 \pm 19$ weeks, with minimum and maximum ages observed as 15 weeks and 33 weeks respectively .Activity hours; working, standing and sleeping hours of all patients were also noted. The mean working hours of the patients were $11.47 \pm 3.04$ hours, the mean sleeping hours were $7.02 \pm 1.38$ 
hours and average standing hours of the patients were $7.07 \pm 2.12$ hours. The average duration of marriage was $10.93 \pm 5.10$ years. Most of the females came from urban areas (80\%) while $13.3 \%$ belonged to rural areas and only $10 \%$ came from suburban areas.

Most of the females were house wives $90(60 \%)$, whilst $30(20 \%)$ involved in the teaching profession, $20(13 \%)$ were doctors, whereas $10(6.7 \%)$ were working in the offices. Sitting habit was not good for all females as $90(60 \%)$ females had flexed sitting habit and $60(40 \%)$ had very bad sitting habit which could cause backache.

In the study 80 (53.3\%) females were obese while $70(46.7 \%)$ were non-obese. Both anthropometric groups were compared as per objectives of the study. Mean age of obese patients was calculated as $35.25 \pm 6.16$ years with maximum and minimum ages as 25 and 45 years respectively. Among non-obese patients, mean age was $31.86 \pm 6.95$ with minimum and maximum ages as 22 years and 40 years respectively. Mean gestational age of obese patients was observed as $30.00+2.08$ weeks with minimum and maximum gestational ages to be 27 weeks and 33 weeks respectively. Among non-obese patients, the mean gestational age was $24.57 \pm 6.11$ weeks and the minimum and maximum ages were found as 15 weeks and 31 weeks respectively. Most females presented with gravidity 4 those were $70(46.7 \%)$ while 40 (26.7\%) had gravidity 3 and 20 (13.3\%) had gravidity 5 .

\section{DISCUSSION}

Backache is a widespread problem in pregnant women that can get severe to end in disabling or even worse outcome. About $10 \%$ of women suffer inability from working because of this and over one third women

\begin{tabular}{|c|c|c|c|c|c|c|}
\hline & & Baseline & Week 1 & Week 2 & Week 4 & Week 6 \\
\hline \multirow{6}{*}{ Obese } & None & - & - & 40 & 50 & 70 \\
\hline & Mild & - & 20 & 10 & 20 & - \\
\hline & Moderate & - & 20 & 30 & 10 & 10 \\
\hline & Severe & 40 & 40 & - & - & - \\
\hline & Worst possible pain & 40 & - & - & - & - \\
\hline & Total & 80 & 80 & 80 & 80 & 80 \\
\hline \multirow{6}{*}{ Non-Obese } & None & - & - & 30 & 70 & 70 \\
\hline & Mild & - & 10 & 40 & - & - \\
\hline & Moderate & - & 50 & - & - & - \\
\hline & Severe & 60 & 10 & - & - & - \\
\hline & Worst possible pain & 10 & - & - & - & - \\
\hline & Total & 70 & 70 & 70 & 70 & 70 \\
\hline \multicolumn{2}{|r|}{ chi-square } & 21.429 & 33.673 & 48.98 & 32.813 & 9.375 \\
\hline \multicolumn{2}{|r|}{$p$-value } & $0.000^{\star}$ & $0.000^{*}$ & $0.000^{*}$ & $0.000^{\star}$ & $0.002^{*}$ \\
\hline
\end{tabular}




\begin{tabular}{|l|c|c|c|c|c|}
\hline \multicolumn{2}{|c|}{} & \multicolumn{2}{c|}{ Pain assessment } & \multirow{2}{*}{ Total } \\
\cline { 2 - 6 } \multicolumn{2}{|c|}{} & Severe & Worst possible pain & \\
\hline \multirow{2}{*}{ Obese } & \multirow{2}{*}{ Final visit } & None & 40 & 30 & 70 \\
\cline { 2 - 6 } & & Moderate & - & 10 & 10 \\
\cline { 2 - 6 } & \multicolumn{2}{|c|}{ Total } & 40 & 40 & 80 \\
\hline \multirow{2}{*}{ Non-Obese } & Final visit & Non & 10 & 60 & 70 \\
\cline { 2 - 6 } & \multicolumn{2}{|c|}{ Total } & 10 & 60 & 70 \\
\hline
\end{tabular}

Table-II. Distribution of reduction in severity of pain at first at final follow-up in both study groups

Chi-square $=11.429$

$p$-value $=0.001^{*}$

report that it interferes their daily life routine ${ }^{22}$. Various measures like bed rest, corsets, traction and physical treatment are taken for the management of backache in pregnancy but most of these prove insignificant ${ }^{23}$ physiotherapy, however, is an autonomous profession and practice reflection. Systematic clinical reasoning is used in a problem solving approach to patient-centered care $^{24}$. Our study aimed to evaluate the frequency of backache in pregnant women with special regard to obesity. We found the backache to be a common problem in pregnancy in our setting too, in which factors like age and height were not directly related to its occurrence. Similar results were demonstrated in a study carried out in 1996 that showed no association between backache during pregnancy with height and weight. Additionally, in that study the backache was more frequent among multigravidas especially grand multigravidas contrarily to the results of our study ${ }^{25}$.

Although, the exact etiology of backache is not known well, it is assumed that local inflammation and other aggravating factors like physical strenuous work and odd posture can contribute in its incidence. In our study too, most of the females had very bad sitting habit which could be the cause of backache. Majority of the females (110 females) reported that their backache was started in the $1^{\text {st }}$ trimester, and only 40 females reported that they developed pain in the $2^{\text {nd }}$ trimester. However, another study showed the incidence of backache to be at its height in the third trimester $^{26}$ at base line visit, there were 50 patients who had severe backache while 100 patients had worse possible pain which was regressed to no pain in 140 patients at follow up visits and only 10 had moderate pain after the application of physiotherapy. Hence, it is evident that physiotherapy was effective in back pain relief during pregnancy as indicated by several other researches ${ }^{27-34}$.

Overall, in our study both groups were compared for severity of pain and it was noticed that on each followup visit there was significant difference between both groups for reduction of severity of pain. However, it was more effective in non-obese patients as compared to obese ones that suggest a better and quick recovery in non-obese patients. Back care advice and exercise during second half of pregnancy significantly reduces backache. Postural education can also play a role to prevent unnecessary mechanical stress on the back therefore neutral postures as well as careful physical activities are recommended. Some patients report that there is some measurable reduction in pain with both acupuncture and physiotherapy. Moreover with acupuncture though, but this better result may be explained due to a reflection of personal care given by acupuncturist as compared with a group therapy from 
the physiotherapists ${ }^{28}$. The role of physiotherapy in its affectivity to reduce backache in pregnant women is imperative and control of obesity during pregnancy may reduce the chances of this problem and enhance the outcome of its management.

\section{CONCLUSIONS}

It is concluded from our study that physiotherapy is effective in reducing the backache in pregnant females and has no side effects on fetus and mother. Also, more effective results can be achieved through physiotherapy in non-obese patients compared to obese patients. Thus, Physiotherapy can be recommended as the first line treatment for pregnant females.

\section{Copyright@C 09 Apr, 2013.}

\section{REFERENCES}

1. Wu W, Meyer O, Uegaki K, Mens JM, van Dieën JH, Wuisman $\mathrm{Pl}$, et al. Pregnancy-related pelvic girdle pain, 1: terminology, clinical presentation and prevalence. Eur Spine J 2004;13:575-89.

2. Ostgaard HC, Andersson GBJ, Karlsson K. Prevalence of back pain in pregnancy. Spine 1991;16:549-52.

3. Ostgaard H, Zetherstrom G, Roos-Hansson E, Svanberg $B$. Reduction of back and posterior pelvic pain in relation to pregnancy. Spine 1994;19:894-900.

4. Low back Pain during pregnancy. 2010. [online]. Http://www.babycenter.com/0_low-back-pain-duringpregnancy_9402.bc.

5. Kausar S, Tajammul A, Sheikh S, Iqbal S, Anwar S. Frequency of backache in pregnancy women attending antenatal clinic. Pak Armed Forces J 2007; 4.

6. Back pain, London home visit physiotherapy treatment. 2011. [Online]. Http://www.mummys physio.com/main_dosuk.html.

7. Abramson D, Summer M, Wilson P. Relaxation of the pelvic joints in pregnancy. Surg Gynecol Obstet 1934;58:595-613.
8. Heyman J, Lundqvist A. The symphysis pubis in pregnancy and parturition. Acta Obstet Gynecol Scand 1932;191-226.

9. Lehmann L. Over het uiteenwijken (diductio, diastasis) der kraakbeenachtige geledingen van het bekken gedurende de baring. Ned Tijdschr Geneesk 1861;5:49-55.

10. Walde J. Obstetrical and gynaecological back and pelvic pains, especially those contracted during pregnancy. Obstet Gynecol Scand 1962;2:11-53.

11. Snelling FG. Relaxation of the pelvic symphyses during pregnancy and parturition. Am J Obstet Dis Women Child 1870;Il:561-96.

12. Goldthwait JE, Osgood RB. A consideration on the pelvic articulations from an anatomical, pathological and clinical standpoint. Boston Med Surg J 1905;152:593-601.

13. Genell S. Studies on insufficientia pelvis (gravidarum et puerperarum). Acta Obstet Gynecol Scand 1949;28:1-33.

14. Bjo"rklund K, Bergstro"m S, Nordstro"m M-L, Ulmsten $U$. Symphyseal distention in relation to serum relaxin levels and pelvic pain in pregnancy. Acta Obstet Gynecol Scand 2000;79:269-75.

15. Hansen A, Jensen DV, Larsen E, Wilken-Jensen C, Petersen LK. Relaxin is not related to symptom-giving pelvic girdle relaxation in pregnant women. Acta Obstet Gynecol Scand 1996;75:245-9.

16. Chamberlain WE. The symphysis pubis in the roentgen examination. Am J Roentgenol Radium Ther 1930;24:621-5.

17. Skajaa K. Om svangerskapopbl tning av bekkenets ledd og smerter som f lge herav. Norsk magasin fo" $\mathrm{rl}$ gevidenskaben 1929;90:713-29.

18. Melzack R. The McGill pain questionnaire: major properties and scoring methods. Pain 1975;1:277-99.

19. Ransford AO, Cairns D, Vert M. The pain drawing as an aid to the psychologic evaluation of patients with lowback pain. Spine 1976;1:127-1234. 
20. Mantle MJ, Greenwood RM, Currey HL. Backache in

27. Kausar S, Tajamul A, Sheikh S. Backache in pregnancy. Biomedica 2006;22:12-5.

pregnancy. Rheumatol Rehabil 1977;16:95-101.

21. Sturesson B, Uden G, Uden A. Pain pattern in pregnancy and "catching" of the leg in pregnant women with posterior pelvic pain. Spine 1997; 22:1880-3.

22. Berg G, Hammar M, Moller-Nielsen J, Linden U, Thorblad J. Low back pain during pregnancy. Obstet Gynecol 1988; 71:71-5.

23. Fast A, Shapiro D, Ducommun EJ, Friedmann LW, Bouklas $T$, Floman $Y$. Low back pain in pregnancy. Spine 1987; 12:368-71.

24. Jayson MIV. ABC of work related disorders: back pain. BrMed J 1996;313:355-8.

25. Deyo RA. Acute low back pain: a new paradigm for management. Br Med J 1996;313:1343-4.

26. Dale E, Mullinax K. Physiological adaptations and considerations of pregnancy. In: Wilder E. Clinics in Physical Therapy: Obstetrics and Gynecological Physical Therapy. New York, NY: Churchill Livingstone Inc; 1988.

28. Ayanniyi 0, Sanya A0, Ogunlade SO, Oni-Orisan MO. Prevalence and pattern of back pain among pregnant women attending antenatal clinics in selected health care facilities. Afr J Biomed Res 2006;9:149-56.

29. Garshasbi A, Faghih Zadeh S. The effect of exercise on the intensity of low back pain in pregnant women. Int $J$ Gynaecol Obstet 2005;88(3):271-5.

30. Intveld E, Cooper S, van Kessel G. The effect of aquatic physiotherapy on low back pain in pregnant women. Int J Aquat Res Edu 2010;4(2):147-52.

31. Sabino J, Grauer JN. Pregnancy and low back pain. Curr Rev Musculoskelet Med 2008;1:137-41.

32. Meeusen R. Praktijkgids Rug-en nekletsels deel1. Kluwer 2001;154-56.

33. Young G, Jewell D. Interventions for preventing and treating pelvic and back pain in pregnancy. Cochrane Database Syst Rev 2002;(1): Cd001139.

34. Stones RW, Vits K. Pelvic girdle pain in pregnancy: Exercises may help, and evidence is increasing that acupuncture reduces pain. $\mathrm{Br}$ Med $\mathrm{J} 2005$; 331(7511): 249-50.

\section{AUTHOR(S):}

1. DR. NADEEM SHAHZAD

(FCPS, DMRT),

Assistant Professor of Obs \& Gyne

King Edward Medical University/ Unit-III

Lady Willingdon Hospital, Lahore.

2. FARHAT ASLAM (DPT)

Doctor of physiotherapy

King Edward Medical University, Lahore.

3. DR. AISHA MALIK

(FCPS, MRCOG)

Professor of Obs \& Gyne

King Edward Medical University/ Unit III

Lady willingdon Hospital, Lahore

\section{ASIF HANIF}

(MSc. Biostatistics, MS. Applied Statistics).

Assistant Professor of Biostatistics

Gulab Devi PGMI, Lahore.

Correspondence Address:

Dr. Nadeem Shahzad

Assistant Professor Unit-III

Lady Willingdon Hospital Ravi Road Lahore

nadeemgoraya@hotmail.com 